\title{
THE STUDY OF SOCIO-DEMOGRAPHIC PROFILE OF ORGANOPHOSPHORUS POISONING IN UTTAR PRADESH
}

\author{
Anurag Srivastava1, Pankaj Kumar Mishra², Anil Kumar Garg ${ }^{3}$, Ankita Srivastava ${ }^{4}$, Pragati Srivastava ${ }^{5}$ \\ ${ }_{1}^{1}$ Assistant Professor, Department of General Medicine, Mayo Institute of Medical Sciences, Barabanki, Uttar Pradesh, India. \\ 2Professor, Department of Community Medicine, Mayo Institute of Medical Sciences, Barabanki, Uttar Pradesh, India. \\ ${ }^{3}$ Assistant Professor, Department of Medicine, SMMH Medical College, Saharanpur, Uttar Pradesh, India. \\ ${ }^{4}$ Resident, Department of Paediatrics, U. P. Rural Institute of Medical Sciences and Research, Saifai, Etawah, Uttar Pradesh, India. \\ ${ }_{5}^{5}$ Assistant Professor, Department of Pharmacology, Goel Institute of Pharmacy and Sciences, Lucknow, Uttar Pradesh, India.
}

ABSTRACT

\section{RESEARCH QUESTION}

What are the socio-demographic profile trends of Organophosphorus poisoning in Uttar Pradesh.

\section{DESIGN}

Prospective study; Interview technique.

\section{SAMPLE SIZE}

A total of 41 cases of OP poisoning were studied. All the information was recorded on a specially prepared Performa which included age, sex, duration of poisoning, amount of poisoning and way of poisoning.

\section{RESULT}

In this study $85 \%$ patients belonged to 15 years' to 30 years' age group, most of them $60.9 \%$ were female patients; $65.9 \%$ patients belonged to rural areas and $34.1 \%$ patients belonged to urban areas; $51.2 \%$ patients were admitted to our side with complaint of organophosphate poisoning within 12 hours; $41.5 \%$ patients were unable to tell the amount of poisoning they exposed; $24.4 \%$ had just exposed or taken less than 5 grams of poison and 34.1\% had taken the poisoning more than 5 grams. Most of the patients, 78.6\% had taken organophosphate for suicidal purpose and $21.4 \%$ patients were exposed to poison accidentally. Ratio of suicidal to accidental poisoning in rural areas is 2.4:1 and in urban areas is 3.7:1.

\section{KEYWORDS}

Organophosphate Poisoning (OP), Suicidal, Accidental.

HOW TO CITE THIS ARTICLE: Srivastava A, Mishra PK, Garg AK, et al. The study of socio-demographic profile of organophosphorus poisoning in Uttar Pradesh. J. Evolution Med. Dent. Sci. 2016;5(54):3604-3606, DOI: 10.14260/jemds/2016/830

\section{INTRODUCTION}

Poisons are subtle and silent weapons which can be easily used without violence and often without arising suspicion. ${ }^{1}$ Organophosphate based pesticides are widely used and have emerged as the major contributors to ill health associated with pesticides worldwide. Organophosphate Poisoning (OP) are the most common suicidal poison in developing countries and mortality continue to increase. Most of these poisons are usually ingested with a suicidal intent. ${ }^{2}$ Because the organophosphorus compounds are readily available, relatively cheap and have a rapidly lethal action, even in smaller doses they are widely used as suicidal poisons. ${ }^{3}$

At present due to the vast development in all the fields of life like industries, medicine and agriculture, a significant number of new compounds have appeared as new poisonous substances. Organophosphorus (OP) compounds can produce significant pesticide related illness and death in developing countries. Acute Organophosphate (OP) poisoning is a

Financial or Other, Competing Interest: None.

Submission 06-05-2016, Peer Review 02-06-2016,

Acceptance 09-06-2016, Published 05-07-2016.

Corresponding Author:

Dr. Anurag Srivastava,

D-3/551, Vineet Khand,

Gomati Nagar,

Lucknow-226010

Uttar Pradesh.

E-mail: anuragmlb@yahoo.com

DOI: $10.14260 /$ jemds $/ 2016 / 830$ significant cause of morbidity and mortality in developing countries including India.

The various factors that can be held responsible for selfpoisoning are emotional disturbance, chronic diseases, loss in the business or failure in examination. While as accidental poisoning occurs mostly due to bites and stings and in children.4,5

A study was conducted on the patients of acute organophosphate poisoning, admitted in Department of Medicine, LLR Hospital, Kanpur. The aim of present study was to know socio-demographic profile trend and clinical outcomes of organophosphorus poisoning.

\section{MATERIALS AND METHODS}

The prospective study was conducted in Department of Medicine of LLR Hospital, Kanpur. The patients of acute organophosphate poisoning admitted to inpatient department had been taken for the study. A total of 41 cases of OP poisoning were studied. All the information was recorded on a specially prepared Performa which included Age, Sex, Area, Duration of poisoning, Amount of poisoning and Way of poisoning. The analysis was done in the form of percentages.

\section{OBSERVATIONS AND RESULT}

In this study, $85 \%$ patients belong to 15 years' to 30 years' age group and $14.6 \%$ belong to 31 years to 45 years' age group. Mean age of patients of rural areas and urban areas is $23.52 \pm 6.54$ and $24.29 \pm 6.18$ respectively. 
Most of patients, $60.9 \%$ were female and $39.1 \%$ were male patients. Female-to-male ratio was 1.6:1 suggesting that poisoning was more in case of female (More than one and a half times) as compared to male.

\begin{tabular}{|c|c|c|c|c|c|c|}
\hline \multirow{2}{*}{$\begin{array}{c}\text { Age } \\
\text { (Years) }\end{array}$} & \multicolumn{2}{|c|}{$\begin{array}{c}\text { Rural } \\
(\text { No=27) }\end{array}$} & \multicolumn{2}{c|}{$\begin{array}{c}\text { Urban } \\
(\text { No=14) }\end{array}$} & \multicolumn{2}{c|}{$\begin{array}{c}\text { Total } \\
(\text { No=41) }\end{array}$} \\
\cline { 2 - 7 } & No. & $\mathbf{\%}$ & No. & $\mathbf{\%}$ & No. & \% \\
\hline $15-30$ & 23 & 85.2 & 12 & 85.7 & 35 & 85.4 \\
\hline $31-45$ & 4 & 14.8 & 02 & 14.3 & 6 & 14.6 \\
\hline \multicolumn{6}{|c|}{ Age Distribution of the Patients } \\
\hline
\end{tabular}

\begin{tabular}{|c|c|c|}
\hline \multirow{2}{*}{ Sex } & \multicolumn{2}{|c|}{ No. of Patients } \\
\cline { 2 - 3 } & No. & \% \\
\hline Male & 16 & 39.1 \\
\hline Female & 25 & 60.3 \\
\hline Total & $\mathbf{4 1}$ & $\mathbf{1 0 0}$ \\
\hline \multicolumn{2}{|c|}{ Sex Distribution of the Patients } \\
\hline
\end{tabular}

\begin{tabular}{|c|c|c|}
\hline \multirow{2}{*}{ Area } & \multicolumn{2}{|c|}{ No. of Patients } \\
\cline { 2 - 3 } & No. & $\mathbf{\%}$ \\
\hline Rural & 27 & 65.9 \\
\hline Urban & 14 & 34.1 \\
\hline Total & 41 & 100 \\
\hline \multicolumn{2}{|c|}{ Area Wise Distribution of the Patients } \\
\hline
\end{tabular}

Out of 41 patients, $27(65.9 \%)$ patients belonged to rural areas and $14(34.1 \%)$ patients belonged to urban areas.

Ratio of patients belonging to rural areas to patients belonging to urban areas was 1.9:1.

Out of 41 patients, $51.2 \%$ were admitted to our side with complaint of organophosphate poisoning within 12 hours and $48.8 \%$ patients were admitted with poisoning more than 12 hours suggesting that number of those patients admitted within 12 hours of poisoning was more than those patients admitted with poisoning more than 12 hours.

\begin{tabular}{|c|c|c|}
\hline $\begin{array}{c}\text { Duration of Poisoning } \\
\text { (Hours) }\end{array}$ & No. of Cases (41) & \% \\
\hline$<12$ & 21 & 51.2 \\
\hline$>12$ & 20 & 48.8 \\
\hline Total & $\mathbf{4 1}$ & $\mathbf{1 0 0}$ \\
\hline
\end{tabular}

No. of Patients According to Duration of Poisoning

\begin{tabular}{|c|c|c|}
\hline Amount of Poisoning & No. of Patients & \% \\
\hline$<5$ Grams & 10 & 24.4 \\
\hline > 5 Grams & 14 & 34.1 \\
\hline Unknown & 17 & 41.5 \\
\hline Total & $\mathbf{4 1}$ & $\mathbf{1 0 0}$ \\
\hline Distribution of Patients According \\
to Amount of Poisoning
\end{tabular}

Out of 41 patients, $41.5 \%$ were unable to tell the amount of poisoning they exposed; $24.4 \%$ had just exposed or taken less than 5 grams of poison and $34.1 \%$ had taken the poison more than 5 grams.

\begin{tabular}{|c|c|c|c|c|c|c|}
\hline \multirow{2}{*}{$\begin{array}{c}\text { Way of } \\
\text { Poisoning }\end{array}$} & \multicolumn{2}{|c|}{$\begin{array}{c}\text { Rural } \\
(\mathbf{N}=\mathbf{2 7})\end{array}$} & \multicolumn{2}{c|}{$\begin{array}{c}\text { Urban } \\
(\mathbf{N = 1 4 )}\end{array}$} & \multicolumn{2}{c|}{$\begin{array}{c}\text { Total } \\
(\mathbf{N = 4 1 )}\end{array}$} \\
\cline { 2 - 7 } & No. & $\mathbf{\%}$ & No. & $\mathbf{\%}$ & No. & \% \\
\hline Suicidal & 18 & 66.7 & 11 & 78.6 & 29 & 70.7 \\
\hline Accidental & 09 & 33.3 & 03 & 21.4 & 12 & 29.3 \\
\hline
\end{tabular}

Most of the patients belonged to rural areas, 70.3\% patients have taken organophosphate for suicidal purpose and 29.6\% patients were exposed to poison accidentally. In Urban areas, $78.6 \%$ patients have taken organophosphate for suicidal purpose and $21.4 \%$ patients were exposed to poison accidentally. Ratio of suicidal to accidental poisoning in rural areas is $2.4: 1$ and in urban areas is 3.7:1.

\section{DISCUSSION}

Organophosphate Poisoning (OP) is common in India, as ours is an agriculturally based society and as the OP compounds are easily available at a cheap rate. Organophosphates are the commonest class of pesticides, which have been implicated in cases of poisoning. 6,7

A majority of the victims were in the age group of 15-30 years, (In the present study, it was $85.4 \%$ ) indicating that organophosphate poisoning is more common in younger age group, which is similar to that in other studies.8,9,10 This age group was the most active one, physically, mentally and socially and so it was more prone to stress during life. Only six cases, which were seen belonged to 31 to 45 years' age group.

The present study had more number of OP cases from the rural areas as compared to Urban areas. Because these compounds are used as pesticides, they are easily available in the Rural areas. Even we could think of changing trends in the rural population.

In the study, we found that out of 41 patients, $25(60.9 \%)$ were female and 16 (39.1\%) were male. Female-to-male ratio was 1.6:1 suggesting that poisoning was more in case of female (More than one and a half times) as compared to male. It observed that the incidence of suicide is high, affecting more females. ${ }^{11}$ One of the reasons for higher incidence of poisoning in females is that females are emotionally more labile than males.

In this study, we found that $51.2 \%$ patients were admitted to our side with complaints of organophosphate poisoning within 12 hours and $48.8 \%$ were admitted with poisoning more than 12 hours suggesting that incidence of those patients admitted within 12 hours of poisoning was more than those patients admitted with complaint of poisoning more than 12 hours. Most of the patients, $41.5 \%$ were unable to tell the amount of poisoning they exposed; $24.4 \%$ had just exposed or taken less than 5 grams of poison and $34.1 \%$ had taken the poisoning more than 5 grams.

In most of the patients poisoning was associated with suicidal tendencies, $70.7 \%$ had taken organophosphate for suicidal purpose and $29.3 \%$ were exposed to poison accidentally. Ratio of suicidal to accidental poisoning in rural areas was 2.4:1 and in urban areas was 3.7:1 suggesting that suicidal poisoning was more as compared to accidental poisoning either in rural areas or urban areas. ${ }^{12}$

\section{CONCLUSION}

The present study helps to interpret the pattern of trends of poisoning as the commonest method of committing suicide and organophosphate compounds are choice of poison in Uttar Pradesh region. Rural people are more prone to poisoning due to occupational hazards and day-to-day problems and rain dependent profession. It is obvious that the younger generation, especially female has become the victims of OP poisoning with the number of cases increasing every year. 
The organophosphorus agents who are used in the agricultural industry are readily available as over-the-counter drugs in village shops and are easily accessible in the village households, hence they act as common agents for suicidal purposes following trivial day-to-day stresses. Present study highlights the problem of organophosphorus poisoning in this region. It is essential to establish strict policies against the sale and availability of insecticides and pesticides and their safer storage at village households to prevent both suicidal and accidental poisoning. It is important to design an appropriate health education programme for the prevention of both suicidal and accidental OP poisoning for the benefit of the public at large.

\section{REFERENCES}

1. Kora SA, Doddamani GB, Halagali GR, et al. Sociodemographic profile of the organophosphorus poisoning cases in southern India. Journal of clinical and diagnostic research 2011;5(5):953-6.

2. Lall SB, Peshin SS, Seth SS. Acute poisoning: a ten years study. Ann Natl Acad Med Sci (India) 1994;30:35-44.

3. Palimar V, Saralaya KM, Arun M, et al. The profile of methyl parathion poisoning in Manipal, India. J Ind Soc Toxicol 2005;1(2):35.

4. Singh B, Unnikrishnan B. A profile of acute poisoning at Mangalore (South India). JCFM 2006;13(3):112-6.

5. Jesslin J, Adepu R, Churi S. Assessment of prevalence and mortality incidence due to poisoning in a south Indian tertiary care teaching hospital. Indian J Pharm Sci 2010;72(5):587-91.
6. Sinha US, Kapoor AK, Agnihotri AK, et al. A profile of the poisoning cases which were admitted to the SRN hospital Allahabad with a special reference to aluminium phosphide poisoning. J Forensic Med Toxicol 1999;16(1):40-3.

7. Dash SK, Mohanty MK, Patnaik KK, et al. The sociodemographic profile of the poisoning cases. J Ind Acad Forensic Med 2005;27(3):133-8.

8. Karki P, Hansdak SG, Bhandari S, et al. A clinicoepidemiological study of organophosphorus poisoning at a rural bases teaching hospital in eastern Nepal. Trop Doct 2001;31(1):32-4.

9. Sahin HA, Sahin I, Arabaci F. Socio-demographic factors in organophosphorus poisoning: a prospective study. Hum Exp Toxicol 2003;22(7):349-53.

10. Nigam M, Jain AK, Dubey BP, et al. Trends of organophosphorus poisoning an autopsy based study. J Ind Acad Forensic Med 2004;26(2):62-5.

11. Jaga $K$, Dharmani C. The interrelation between organophosphate toxicity and the epidemiology of depression and suicide. Rev Environ Health 2007;22(1):57-73.

12. Kar N. Lethality of suicidal organophosphorus poisoning in an Indian population: exploring preventability. Annals of General Psychiatry 2006;5:17. 